\title{
Adaptation costs for climate change-related cases of diarrhoeal disease, malnutrition, and malaria in $\mathbf{2 0 3 0}$
} Kristie L Ebi

\author{
Address: ESS, LLC, Alexandria, VA 22304, USA \\ Email: Kristie L Ebi - krisebi@essllc.org
}

\author{
Published: 19 September 2008 \\ Received: 31 August 2007 \\ Globalization and Health 2008, 4:9 doi:10.1186/1744-8603-4-9 \\ Accepted: 19 September 2008 \\ This article is available from: http://www.globalizationandhealth.com/content/4/I/9 \\ (C) 2008 Ebi; licensee BioMed Central Ltd. \\ This is an Open Access article distributed under the terms of the Creative Commons Attribution License (http://creativecommons.org/licenses/by/2.0), \\ which permits unrestricted use, distribution, and reproduction in any medium, provided the original work is properly cited.
}

\begin{abstract}
Background: Climate change has begun to negatively affect human health, with larger burdens projected in the future as weather patterns continue to change. The climate change-related health consequences of diarrhoeal diseases, malnutrition, and malaria are projected to pose the largest risks to future populations. Limited work has been done to estimate the costs of adapting to these additional health burdens.

Methods: The costs of treating diarrhoeal diseases, malnutrition (stunting and wasting only), and malaria in 2030 were estimated under three climate scenarios using (I) the current numbers of cases; (2) the projected relative risks of these diseases in 2030; and (3) current treatment costs. The analysis assumed that the number of annual cases and costs of treatment would remain constant. There was limited consideration of socioeconomic development.

Results: Under a scenario assuming emissions reductions resulting in stabilization at $750 \mathrm{ppm} \mathrm{CO}$ equivalent in 2210 , the costs of treating diarrhoeal diseases, malnutrition, and malaria in 2030 were estimated to be $\$ 4$ to 12 billion. This is almost as much as current total annual overseas development assistance for health.

Conclusion: The investment needs in the health sector to address climate-sensitive health outcomes are large. Additional human and financial resources will be needed to prevent and control the projected increased burden of health outcomes due to climate change.
\end{abstract}

\section{Background}

The health impacts of climate change are diverse and wide-ranging. Weather and climate are among the factors that determine the geographic range and incidence of several major causes of ill health, including undernutrition, which affects $17 \%$ of the world's population in developing countries [1]; diarrhoeal diseases and other conditions due to unsafe water and lack of basic sanitation, which cause 2 million deaths annually, mostly in young children [2]; and malaria, which causes more than a million childhood deaths annually [3]. Table 1 provides the annual incidence of diarrhoeal disease, malnutrition, and malaria by WHO Region in 2002 [countries included in each region are provided in Additional file 1]. The numbers for malnutrition include only stunting and wasting, not all the health impacts, and do not include micronutrient deficiencies, such as of zinc and vitamin $\mathrm{A}$, that also have serious health consequences.

The Fourth Assessment Report of the Intergovernmental Panel on Climate Change concluded that climate change has begun to negatively affect human health, and that pro- 
Table I: Annual incidence of diarrhoeal diseases, malnutrition (stunting and wasting) and malaria by WHO sub-region, 2002

\begin{tabular}{|c|c|c|c|c|c|}
\hline Sub-region & Population (000s) & Diarrhoeal diseases (000s) & Malnutrition (000s) & Malaria (000s) & Total (000s) \\
\hline Afr-D & 301878 & 389842 & 5033 & 180368 & 575243 \\
\hline Afr-E & 353598 & 449192 & 5912 & $17665 \mid$ & 631755 \\
\hline Amr-A & 328176 & 77578 & 137 & 0 & 77715 \\
\hline Amr-B & $437 \quad 142$ & 390590 & $\mathrm{I} 124$ & 2866 & 394580 \\
\hline Amr-D & 72649 & 73271 & 603 & 718 & 74592 \\
\hline Emr-B & $14 \mid 835$ & 96324 & 585 & 363 & 97272 \\
\hline Emr-D & 351256 & 345605 & 4523 & 16898 & 367026 \\
\hline Eur-A & 412512 & 79219 & 134 & 0 & 79353 \\
\hline Eur-B & 219983 & 78509 & 649 & 0 & 79158 \\
\hline Eur-C & 241683 & 47886 & 262 & 0 & 47912 \\
\hline Sear-B & 297525 & 179213 & 2251 & 6951 & 188415 \\
\hline Sear-D & I 262285 & 1051538 & 18040 & 21568 & | 146 | \\
\hline Wpr-A & 154919 & 30026 & 64 & 6 & 30096 \\
\hline Wpr-B & I 546770 & $|225| 88$ & 7035 & 1838 & | 23406 | \\
\hline World & 6122211 & 4513981 & 46352 & 408227 & 4968560 \\
\hline
\end{tabular}

Source: http://www.who.int/healthinfo/bodestimates/en/index.html; accessed 20 May 2007

jected climate change will increase the risks of climatesensitive health outcomes [4]. The climate change-related health consequences of malnutrition, diarrhoeal diseases, and malaria are projected to pose large risks to future populations, particularly in low-income countries in tropical and sub-tropical regions.

The size of the projected impacts raises the question of how much it will cost to treat these additional cases of disease. To further the discussion of adaptation costs, this paper estimates of the costs of interventions to cope with additional cases of malnutrition, diarrhoeal diseases, and malaria due to climate change in 2030. The estimates are for the costs of climate change only. Population growth is not considered and there is limited consideration of socioeconomic development.

\section{Methods}

The data sources used were (1) the current number of cases of diarrhoeal diseases, malnutrition, and malaria [http://www.who.int/healthinfo/bodestimates/en/

index.html; accessed 20 May 2007]; (2) the World Health Organization (WHO) Global Burden of Disease (GBD) study that projected the relative risks associated with climate change in 2030 for a range of climate-sensitive health determinants and outcomes [5]; and (3) published data on the costs of interventions for diarrhoeal diseases, malnutrition, and malaria, primarily from the project 'Disease Control Priorities in Developing Countries' http:/ /www.dcp2.org. Assuming that the current annual number of cases of diarrhoeal diseases, malnutrition, and malaria would remain constant to 2030, the numbers of current cases were multiplied by the relative risks for climate change estimated by the Global Burden of Disease Study (under three different emission scenarios) to esti- mate the number of additional cases of these diseases that could be attributed to climate change in the year 2030 . The numbers of additional cases were multiplied by the current costs of treatment per case to estimate the additional costs of treating climate change-related cases of diarrhoeal diseases, malnutrition, and malaria.

\section{WHO Global Burden of Disease study}

The goals of the World Health Organization (WHO) Global Burden of Disease study were to produce the best possible evidence-based description of population health, the causes of lost health, and likely future trends in health in order to inform policy-making [6]. Twenty-six risk factors, including climate change, were assessed [5]. The GBD used two summary measures of population health, mortality and the Disability Adjusted Life Years lost (DALYs). DALYs provide a better measure than mortality of the population health impacts of diarrhoeal diseases, malnutrition, and malaria. The attributable burden of DALYs for a specific risk factor was determined by estimation of the burden of specific diseases related to the risk factor; estimation of the increase in risk for each disease per unit increase in exposure to the risk factor; and estimation of the current population distribution of exposure, or future distribution as estimated by modelling exposure scenarios. Counterfactual or alternative exposure scenarios to the current distribution of risk factors were created to explore distributional transitions towards a theoretical minimum level of exposure (e.g. for exposure to carcinogens, the theoretical minimum level of exposure would be no exposure).

For climate change, the questions addressed were what will be the total health impact caused by climate change between 2000 and 2030 and how much of this burden 
could be avoided by stabilizing greenhouse gas emissions [5]. The alternative exposure scenarios defined were:

- Unmitigated emission trends (i.e., approximately following the Intergovernmental Panel on Climate Change IS92a or business as usual scenario);

- Emissions reductions resulting in stabilization at 750 ppm $\mathrm{CO}_{2}$ equivalent by 2210 (s750); and

- Emissions reductions resulting in stabilization at 550 ppm $\mathrm{CO}_{2}$ equivalent by 2170 (s550).

Climate change projections were generated by the HadCM2 general circulation climate model [7]. The health outcomes included in the analysis were chosen based on sensitivity to climate variation, predicted future importance, and availability of quantitative global models (or feasibility of constructing them). The health outcomes selected were the direct impacts of heat and cold, episodes of diarrhoeal disease, cases of Plasmodium falciparum malaria, fatal unintentional injuries in coastal floods and inland floods/landslides, and non-availability of recommended daily calorie intake (as an indicator for the prevalence of malnutrition). Global and WHO specific region estimates were generated.

In the year 2000, the mortality attributable to climate change was estimated to be $154,000(0.3 \%)$ deaths, and the attributable burden was 5.5 million $(0.4 \%)$ DALYs, with approximately $50 \%$ of the burden due to malnutrition [5]. About $46 \%$ of the DALYs attributable to climate change were estimated to have occurred in the WHO South-East Asia Region, 23\% in countries in the Africa region with high child mortality and very high adult male mortality, and $14 \%$ in countries in the Eastern Mediterranean region with high child and adult male mortality.

Additional files 2, 3, 4, provide the relative risk estimates for malnutrition, diarrhoeal diseases, and malaria, respectively, projected for 2030 under the alternative exposure scenarios [5]. Lower range relative risk estimates are not shown as they were 1.00 or close to 1.00 .

For diarrhoeal diseases, developing countries were defined as those with per capita incomes less than US $\$ 6,000 /$ year in 1990 US dollars [5]. For such countries, the exposure-response relationship used was a $5 \%$ increase in diarrhoeal incidence per ${ }^{\circ} \mathrm{C}$ increase in temperature. The study assumed that the climate sensitivity of diarrhoea would decrease with increasing GDP; once a country was projected to reach per capita incomes of UD $\$ 6,000 /$ year (as estimated by EMF 14 [8]), then overall diarrhoea incidence was assumed to not respond to changes in temperature. The study assumed that diar- rhoeal incidence in richer countries is insensitive to climate change. The relative risks for each region are a population-weighted average of the countries within the region.

For malnutrition, estimates of national food availability were based on the effects of temperature and precipitation, and the beneficial effects of higher $\mathrm{CO}_{2}$ levels, projected using the IBSNAT-ICASA dynamic crop growth models [9]. Principal characteristics of this model include no major changes in the political or economic context of world food trade or in food production technology; population growth follows the World Bank mid-range estimate (i.e. 10.7 billion by the 2080s); GDP accumulated as projected by EMF14 [8]; and a 50\% trade liberalization in agriculture is introduced gradually by 2020 .

Analyses suggested that the model output was positively related to more direct measures of malnutrition, including incidence of underweight, and stunting and wasting in children $<5$ years of age [5]. The relative risks of malnutrition in Additional file 3 were interpreted as being directly proportional to underweight; this applies to all diseases affected by underweight (including diarrhoea and malaria). The model output was used to generate midrange estimates; the high relative risks were calculated as a doubling of the mid-range estimate.

For malaria, estimates for the projected populations at risk of Plasmodium falciparum malaria were based on the MARA/ARMA model [5]. The model output was used to generate mid-range estimates; the high relative risks were calculated as a doubling of the mid-range estimate. Socioeconomic development was assumed to not affect the incidence of malaria.

\section{Results}

Estimated climate change-related excess incident cases of diarrhoeal diseases, malnutrition, and malaria in $\mathbf{2 0 3 0}$

The total estimated excess incident cases of diarrhoeal diseases, malnutrition, and malaria in 2030 for the three scenarios (unmitigated emissions and stabilization at 550 and $750 \mathrm{ppm} \mathrm{CO}_{2}$ equivalent) are shown in Tables 2, 3 and 4 . Given the current burden of these health outcomes and the relative risks from the Global Burden of Disease study, it is not surprising that the largest increases in climate change-attributable cases are projected to be in Africa and Southeast Asia. Table 5 compares current and projected (under the $750 \mathrm{ppm} \mathrm{CO}_{2}$ scenario) numbers of cases of diarrhoeal diseases, malnutrition, and malaria; climate change is projected to increase the numbers of cases by $3-10 \%$. Smaller increases were projected under the lower emission scenarios. 
Table 2: Projected excess incident cases of diarrhoeal diseases $(000 s)$ for alternative climate scenarios relative to baseline climate (mid and high estimates)

\begin{tabular}{|c|c|c|c|c|c|}
\hline \multirow[t]{2}{*}{ Sub-region } & \multirow[t]{2}{*}{ Climate } & \multicolumn{2}{|c|}{2000} & \multicolumn{2}{|c|}{2030} \\
\hline & & Mid & High & Mid & High \\
\hline \multirow[t]{3}{*}{ Afr-D } & S550 & 3,898 & 11,695 & 19,492 & 38,984 \\
\hline & S750 & 7,797 & 15,594 & 23,391 & 50,679 \\
\hline & UE & 7,797 & 19,492 & 27,289 & 62,375 \\
\hline \multirow[t]{3}{*}{ Afr-E } & S550 & 4,492 & 13,476 & 22,460 & 49,411 \\
\hline & S750 & 8,984 & 17,968 & 26,952 & 58,395 \\
\hline & UE & 8,984 & 22,460 & 35,935 & 71,871 \\
\hline \multirow[t]{3}{*}{ Amr-A } & S550 & 0 & I,552 & 0 & 4,655 \\
\hline & S750 & 0 & 1,552 & 0 & 4,655 \\
\hline & UE & 0 & 1,552 & 0 & 6,206 \\
\hline \multirow[t]{3}{*}{ Amr-B } & S550 & 0 & 7,812 & 0 & 19,530 \\
\hline & S750 & 0 & 7,812 & 0 & 23,435 \\
\hline & UE & 0 & 7,812 & 0 & 31,247 \\
\hline \multirow[t]{3}{*}{ Amr-D } & S550 & 733 & 2,198 & 1,465 & 5,129 \\
\hline & S750 & 1,465 & 2,198 & 1,465 & 5,862 \\
\hline & UE & I,465 & 2,931 & 1,465 & 7,327 \\
\hline \multirow[t]{3}{*}{ Emr-B } & S550 & 963 & 2,890 & 5,779 & 5,779 \\
\hline & S750 & 1,926 & 2,890 & 5,779 & 5,779 \\
\hline & UE & 1,926 & 3,853 & 8,669 & 8,669 \\
\hline \multirow[t]{3}{*}{ Emr-D } & S550 & 6,912 & 10,368 & 0 & 41,472 \\
\hline & S750 & 6,912 & 10,368 & 0 & 44,929 \\
\hline & UE & 10,368 & 17,280 & 0 & 65,665 \\
\hline \multirow[t]{3}{*}{ Eur-A } & S550 & 0 & I,584 & 0 & 4,753 \\
\hline & S750 & 0 & $\mathrm{I}, 584$ & 0 & 4,753 \\
\hline & UE & 0 & I,584 & 0 & 6,338 \\
\hline \multirow[t]{3}{*}{ Eur-B } & S550 & 785 & 2,355 & 785 & 5,496 \\
\hline & S750 & 785 & 2,355 & 785 & 6,281 \\
\hline & UE & 785 & 2,355 & 785 & 7,066 \\
\hline \multirow[t]{3}{*}{ Eur-C } & S550 & 958 & $\mathrm{I}, 437$ & 0 & 3,352 \\
\hline & S750 & 958 & I,437 & 0 & 3,352 \\
\hline & UE & 958 & 1,915 & 0 & 3,831 \\
\hline \multirow[t]{3}{*}{ Sear-B } & S550 & 1,792 & 3,584 & 0 & 8,960 \\
\hline & S750 & I,792 & 5,375 & 0 & 10,753 \\
\hline & UE & 3,584 & 7,169 & 0 & 14,337 \\
\hline \multirow[t]{3}{*}{ Sear-D } & S550 & 21,031 & 1.03 & 63,092 & 136,700 \\
\hline & S750 & 21,031 & 42,062 & 73,608 & $|57,73|$ \\
\hline & UE & 31,546 & 52,577 & 94,638 & 199,792 \\
\hline \multirow[t]{3}{*}{ Wpr-A } & S550 & 0 & 300 & 0 & $\mathrm{I}, 50 \mathrm{I}$ \\
\hline & S750 & 0 & 300 & 0 & $|, 50|$ \\
\hline & UE & 0 & 601 & 0 & 2,102 \\
\hline \multirow[t]{3}{*}{$W_{p r-B}$} & S550 & 12,252 & 36,756 & 0 & 73,511 \\
\hline & S750 & 12,252 & 36,756 & 0 & 73,511 \\
\hline & UE & 24,504 & 61,259 & 12,252 & 110,267 \\
\hline
\end{tabular}

Annual costs of interventions for diarrhoeal diseases, malnutrition, and malaria

Annual costs of intervention for diarrhoeal diseases, malnutrition, and malaria http://www.dcp2.org were based on currently deployed interventions and did not include costs of implementing programs (including infrastructure and health care personnel costs) in new areas if these diseases increase their geographic range, as is projected. The costs of initiating programs in new areas can be signifi-
Table 3: Projected excess incident cases of malnutrition (000s) for alternative climate scenarios relative to baseline climate (mid and high estimates)

\begin{tabular}{|c|c|c|c|c|c|}
\hline \multirow[t]{2}{*}{ Sub-region } & \multirow[t]{2}{*}{ Climate } & \multicolumn{2}{|c|}{2000} & \multicolumn{2}{|c|}{2030} \\
\hline & & Mid & High & Mid & High \\
\hline \multirow[t]{3}{*}{ Afr-D } & S550 & 50 & 101 & 151 & 302 \\
\hline & S750 & 50 & 151 & 201 & 453 \\
\hline & UE & 50 & 50 & 101 & 201 \\
\hline \multirow[t]{3}{*}{ Afr-E } & S550 & 59 & 118 & 177 & 355 \\
\hline & S750 & 59 & 118 & 236 & 473 \\
\hline & UE & 59 & 59 & 118 & 296 \\
\hline \multirow[t]{3}{*}{ Amr-A } & S550 & 0 & 0 & 0 & 0 \\
\hline & S750 & 0 & 0 & 0 & 0 \\
\hline & UE & 0 & 0 & 0 & 0 \\
\hline \multirow[t]{3}{*}{ Amr-B } & S550 & 22 & 34 & 56 & 112 \\
\hline & S750 & 34 & 79 & 134 & 247 \\
\hline & UE & 0 & 0 & 0 & 0 \\
\hline \multirow[t]{3}{*}{ Amr-D } & S550 & 12 & 18 & 30 & 133 \\
\hline & S750 & 18 & 42 & 66 & 0 \\
\hline & UE & 0 & 0 & 0 & 0 \\
\hline \multirow[t]{3}{*}{ Emr-B } & S550 & 6 & 12 & 18 & 35 \\
\hline & S750 & 12 & 23 & 35 & 76 \\
\hline & UE & 0 & 0 & 0 & 0 \\
\hline \multirow[t]{3}{*}{ Emr-D } & S550 & 90 & 181 & 317 & 678 \\
\hline & S750 & 136 & 317 & 498 & 995 \\
\hline & UE & 90 & 226 & 362 & 724 \\
\hline \multirow[t]{3}{*}{ Eur-A } & S550 & 0 & 0 & 0 & 0 \\
\hline & S750 & 0 & 0 & 0 & 0 \\
\hline & UE & 0 & 0 & 0 & 0 \\
\hline \multirow[t]{3}{*}{ Eur-B } & S550 & 0 & 0 & 0 & 0 \\
\hline & S750 & 0 & 0 & 0 & 0 \\
\hline & UE & 0 & 0 & 0 & 0 \\
\hline \multirow[t]{3}{*}{ Eur-C } & S550 & 0 & 0 & 0 & 0 \\
\hline & S750 & 0 & 0 & 0 & 0 \\
\hline & UE & 0 & 0 & 0 & 0 \\
\hline \multirow[t]{3}{*}{ Sear-B } & S550 & 45 & 68 & 113 & 225 \\
\hline & S750 & 68 & 135 & 225 & 428 \\
\hline & UE & 0 & 0 & 0 & 23 \\
\hline \multirow[t]{3}{*}{ Sear-D } & S550 & 722 & 1263 & 2165 & 4510 \\
\hline & S750 & 722 & 1804 & 3067 & 6314 \\
\hline & UE & 902 & 1804 & 3067 & 5953 \\
\hline \multirow[t]{3}{*}{ Wpr-A } & S550 & 0 & 0 & 0 & 0 \\
\hline & S750 & 0 & 0 & 0 & 0 \\
\hline & UE & 0 & 0 & 0 & 0 \\
\hline \multirow[t]{3}{*}{$W_{p r-B}$} & S550 & 0 & 70 & 70 & $|4|$ \\
\hline & S750 & 70 & $14 \mid$ & 211 & 352 \\
\hline & UE & 0 & 0 & -70 & 0 \\
\hline
\end{tabular}

cant, and include costs of infrastructure (i.e. building clinics, costs for equipment and drugs), training new personnel, maintenance costs, etc. Excluding the costs of implementing programs that are currently being scaled up across Africa with the help of the Global Fund, the US President's Malaria Initiative, and others, substantially underestimates the cost of controlling malaria. 
Table 4: Projected excess incident cases of malaria (000s) for alternative climate scenarios relative to baseline climate (mid and high estimates)

\begin{tabular}{|c|c|c|c|c|c|}
\hline \multirow[t]{2}{*}{ Sub-region } & \multirow[t]{2}{*}{ Climate } & \multicolumn{2}{|c|}{2000} & \multicolumn{2}{|c|}{2030} \\
\hline & & Mid & High & Mid & High \\
\hline \multirow[t]{3}{*}{ Afr-D } & S550 & 0 & 1804 & 1804 & 3607 \\
\hline & S750 & 0 & 1804 & 1804 & 5411 \\
\hline & UE & 1804 & 1804 & 3607 & 9018 \\
\hline \multirow[t]{3}{*}{ Afr-E } & S550 & 3533 & 7066 & 12366 & 26498 \\
\hline & S750 & 3533 & 8833 & 15899 & 31797 \\
\hline & UE & 7066 & $14 \mid 32$ & 24731 & 49462 \\
\hline \multirow[t]{3}{*}{ Amr-A } & S550 & 0 & 0 & 0 & 0 \\
\hline & S750 & 0 & 0 & 0 & 0 \\
\hline & UE & 0 & 0 & 0 & 0 \\
\hline \multirow[t]{3}{*}{ Amr-B } & S550 & 57 & 115 & 229 & 459 \\
\hline & S750 & 86 & 143 & 287 & 545 \\
\hline & UE & 115 & 258 & 430 & 860 \\
\hline \multirow[t]{3}{*}{ Amr-D } & S550 & 7 & 14 & 29 & 65 \\
\hline & S750 & 7 & 22 & 36 & 72 \\
\hline & UE & 14 & 29 & 57 & 122 \\
\hline \multirow[t]{3}{*}{ Emr-B } & S550 & 0 & 0 & 0 & 0 \\
\hline & S750 & 0 & 0 & 0 & 0 \\
\hline & UE & 0 & 0 & 0 & 0 \\
\hline \multirow[t]{3}{*}{ Emr-D } & S550 & 607 & 1183 & 2535 & 5069 \\
\hline & S750 & 676 & 1352 & 3211 & 6252 \\
\hline & UE & 1014 & 2197 & 4900 & 9970 \\
\hline \multirow[t]{3}{*}{ Eur-A } & S550 & 0 & 0 & 0 & 0 \\
\hline & S750 & 0 & 0 & 0 & 0 \\
\hline & UE & 0 & 0 & 0 & 0 \\
\hline \multirow[t]{3}{*}{ Eur-B } & S550 & 0 & 0 & 0 & 0 \\
\hline & S750 & 0 & 0 & 0 & 0 \\
\hline & UE & 0 & 0 & 0 & 0 \\
\hline \multirow[t]{3}{*}{ Eur-C } & S550 & 0 & 0 & 0 & 0 \\
\hline & S750 & 0 & 0 & 0 & 0 \\
\hline & UE & 0 & 0 & 0 & 0 \\
\hline \multirow[t]{3}{*}{ Sear-B } & S550 & 0 & 0 & 0 & 0 \\
\hline & S750 & 0 & 0 & 0 & 0 \\
\hline & UE & 0 & 0 & 0 & 0 \\
\hline \multirow[t]{3}{*}{ Sear-D } & S550 & 0 & 0 & 0 & 70 \\
\hline & S750 & 0 & 0 & 70 & 70 \\
\hline & UE & 0 & 0 & 70 & 139 \\
\hline \multirow[t]{3}{*}{ Wpr-A } & S550 & 0.4 & 0.8 & 1.5 & 3 \\
\hline & S750 & 0.5 & 1.0 & 2 & 4 \\
\hline & UE & 0.8 & 1.6 & 3 & 6 \\
\hline \multirow[t]{3}{*}{$W_{p r-B}$} & S550 & 110 & 221 & 404 & 790 \\
\hline & S750 & 147 & 276 & 478 & 974 \\
\hline & UE & 221 & 441 & 772 & 1526 \\
\hline
\end{tabular}

There are three major diarrhoea syndromes requiring treatment: acute watery diarrhoea that results in varying degrees of dehydration; persistent diarrhoea that last 14 days or longer, manifested by malabsorption, nutrient losses, and wasting; and bloody diarrhoea caused by inflammation of the intestinal tract. Viruses, bacteria, protozoa, and helminthes can cause diarrhoea. Diarrhoeal diseases affect all populations, with the largest health burdens among the poor. The costs of two sets of intervention for treating diarrhoeal diseases in children under five were estimated: (1) breastfeeding promotion, rotavirus immunization, cholera immunization, and measles immunization; and (2) improvement of water supply and sanitation [10]. The average cost per child in 2001 US\$ for (1) was $\$ 15.09$ (the costs range from $\$ 0.71$ per child for oral rehydration therapy in Indonesia to $\$ 104.30$ per child for rotavirus immunization in South Africa) and for (2) was $\$ 53.00$ ( $\$ 25.00$ for rural areas and $\$ 81.00$ for urban areas).

The average costs of nutritional interventions per child for addressing underweight range from $\$ 17.40$ to $\$ 23.09$, and include breastfeeding promotion, child survival programs (with a nutritional component), nutritional programs, and growth monitoring and counselling [11]. These costs are very conservative; Edejer et al. [12] estimated the annual per capita cost of providing food to improve child health in Africa D and SEAR-D was \$int (international dollar) 116.23 , and the cost per recipient was $\$$ int 310.91 to 317.30 . An international dollar is a hypothetical unit of currency that has the same purchasing power that the US\$ has in the US at a given point in time, thus showing the average value of local currency units within each region's borders. Using these estimates would increase the estimated costs by more than 10-fold.

The costs of two sets of interventions for malaria were estimated: (1) insecticide-treated bednets plus case management with artemisinin-based combination therapy plus intermittent presumptive treatment in pregnancy; and (2) indoor residual spraying plus (1) [13]. The average cost for (1) for Africa D and E was \$int 88.50 and the average cost for (2) was \$int 123.5; these are incremental costs per disability adjusted life year lost and did not include the costs of implementing new malaria control programs. These cost estimates are not on the same basis as those for

Table 5: Comparison of current diarrhoeal disease, malnutrition, and malaria cases with estimated additional cases due to climate change in 2030 assuming the 750 ppm of $\mathrm{CO}_{2}$ scenario (thousands of cases)

\begin{tabular}{|c|c|c|c|}
\hline & Diarrhoeal diseases & Malnutrition & Malaria \\
\hline Current cases & $4,5|3,98|$ & 46,352 & 408,227 \\
\hline Climate change attributable cases in 2030 & $13 \mid, 980$ & 4,673 & 21,787 \\
\hline$\%$ increase & $3 \%$ & $10 \%$ & $5 \%$ \\
\hline
\end{tabular}


diarrhoeal diseases and malnutrition (which were for the cost of treatment intervention per child); however, no adjustments were made in the analysis.

Table 6 summarizes the projected excess costs in millions of US\$ in 2030 to manage the excess cases of diarrhoeal diseases, malnutrition, and malaria due to climate change under the three scenarios. The total costs under S550 were estimated to be $\$ 3,333$ to $\$ 10,689$ million; the total costs under $\$ 750$ were $\$ 3,992$ to $\$ 12,603$ million; and the total costs under UE were $\$ 5,852$ to $\$ 17,957$ million.

\section{Current health expenditures}

Poor countries tend to have low health expenditures and to rely significantly on external donors [3]. Currently, there are a number of donors interested in investing in health, which is increasing overseas development assistance. Bilateral assistance for health rose from an annual average of US $\$ 2.2$ billion during 1997-99 to US $\$ 2.9$ billion in 2002 (Table 7) [14]. Within the UN system, development assistance rose from an annual average of US\$ 1.6 billion during 1997-99 to US\$2 billion in 2002. Commitments from the development banks remained stationary at about US\$1.4 billion. However, changes in accounting at the World Bank to include financing for health-related activities in other sectors (i.e. water and sanitation, transportation, and social development), suggest that new commitments rose from about US\$ 1 billion in 2001 to US\$1.7 billion in 2003.

Therefore, for the $750 \mathrm{ppm} \mathrm{CO}_{2}$ scenario, the annual needs in 2030 would be almost as much as current total annual overseas development assistance for health. The estimate of investment needs does not account for socioeconomic changes, in particular increased population and income. Assuming the estimated costs of treatment per case do not differ between baseline cases and cases due to climate change, the total investment needs in 2030 for combating diarrhoeal disease would be $\$ 67$ billion, malnutrition $\$ 2$ billion, and malaria $\$ 36$ to $\$ 50$ billion.

\section{Discussion}

Estimating the adaptation needs in the health sector is challenging. Most of the health outcomes that are pro- jected to be affected by climate change are current problems; there will not be death certificates, hospital admissions, or records of visits to health care providers indicating that a particular event was due to climate change. Instead, as with some other environmental exposures (particularly indoor and outdoor air quality), models are used to estimate the proportion of a disease burden that can be attributed to climate change based on exposure-response relationships and projected changes in weather patterns. Uncertainties in models, from limited data through to inadequate specification of factors that influence the exposure-response relationship, will therefore lead to uncertainty as to the precise magnitude of the climate change impact.

The analysis makes a number of necessary, but unlikely assumptions, including that the number of annual cases of diarrhoeal disease, malaria, and malnutrition, and the cost of treatment would remain constant. Population growth is projected to increase under the medium variant from 6.1 billion in 2000 to 8.3 billion in 2030 [15]. Conducting a sensitivity analysis that incorporated these population increases would require assumptions of future incidence rates of these health outcomes, based on assumptions of socioeconomic development, including improvements in health care delivery, the rate of deployment of current interventions, and the development of more effective technologies. Using the current number of cases in the analysis in effect assumes that incidence will decrease as population increases, without attribution of the possible reasons for such a decline. If disease rates remain constant until 2030, then the number of cases due to climate change would increase.

Because of the large uncertainties, the costs estimated should be viewed only as indicators of the relative magnitude of health adaptation costs. Countries improve their public health and health care systems as they develop, which should decrease the burden of many climate-sensitive diseases. Costs of current treatments tend to decrease over time, although development of new, more effective treatments may cost more. However, there is an underlying assumption that currently developing countries will develop along similar pathways to those followed by the

Table 6: Projected excess costs (million US\$) in 2030 to manage climate change-related cases of diarrhoeal diseases, malnutrition, and malaria for three alternative climate scenarios relative to baseline climate (mid and high estimates)

\begin{tabular}{lcccccc}
\hline Scenario & \multicolumn{2}{c}{ Diarrhoeal Diseases } & \multicolumn{2}{c}{ Malnutrition } & \multicolumn{2}{c}{ Malaria } \\
\hline & Mid & High & Mid & High & Mid & High \\
\hline S550 & 1,706 & 6,024 & $53.9-71.5$ & $112.9-149.9$ & $1,573-2,145$ & $3,236-4,515$ \\
S750 & 1,983 & 6,814 & $81.3-107.9$ & $162.5-215.6$ & $1,928-2,691$ & $3,994-5,573$ \\
UE & 2,731 & 9,010 & $62.2-82.6$ & $125.2-166.2$ & $3,059-4,269$ & $6,293-8,781$
\end{tabular}


Table 7: Development assistance for health, selected years (millions US\$)

\begin{tabular}{lcc}
\hline Source & Annual Average, $1997-1999$ & $\mathbf{2 0 0 2}$ \\
\hline Bilateral agencies & 2560 & 2875 \\
Multilateral agencies & 3402 & 4649 \\
European Commission & 304 & 244 \\
Global Fund to Fight AIDS, Tuberculosis, and Malaria & 0 & 962 \\
Bill \& Melinda Gates Foundation & 458 & 900 \\
Total & 6724 & 9330 \\
\hline
\end{tabular}

Source: Hecht and Shah [14]

developed countries. There is ample evidence to suggest that the reality may be much more challenging. A key issue is water; most developing countries do not have as much available water as developed countries did when they were developing. Therefore, it will be more difficult to resolve issues such as access to safe water and sanitation. Also, malaria is much more difficult to control in Africa than it was in Europe and the US.

Another complexity is estimating the economic cost of injuries, illnesses, and deaths across multiple countries and regions. Issues include not just how to value a human life, but how to measure economically the life-course consequences of malnutrition, for example. Mortality is a commonly used metric, but is an inadequate measure of the affect of a health outcome on the family and on society; a death at age 80 and a death at age 2 would be counted equally while having different impacts. Similarly, malnutrition decreases learning ability, thus affecting lifelong earning potential, among a myriad of other impacts. Therefore, counting cases of disease also is insufficient for estimating total impacts.

Additional research could reduce some of the uncertainties in the analysis. The literature base underlying the exposure-response relationships is fairly thin; additional estimates in more regions would increase confidence in projected relative risks and would allow estimates of future climate change-attributable cases on smaller spatial scales. Additional research also is needed to better project how population growth, socioeconomic development, and other factors would likely influence future rates of climate-sensitive health determinants and outcomes. Development of a health model would facilitate both projections and identification where additional information would reduce uncertainty [16]. Linking such a model with integrated assessment models would take advantage of the their efforts to model population growth and economic development.

Bosello et al. [17] estimated the economic impacts of climate change in 2050 on temperature-related illnesses, diarrhoeal diseases, malaria, dengue fever, and schistosomiasis. Changes in morbidity and mortality were inter- preted as changes in labour productivity and demand for health care. There was a mixed pattern of increases and decreases in GDP, welfare, and investment across world regions, with benefits estimated in high-income countries and losses primarily in low-income countries. The results showed that direct cost estimates, such as the present analysis, underestimate the full health costs (and benefits) of climate change.

Because of the uncertainties in the estimated costs, they should be taken as indicators of the size of the financial needs and not as accurate predictions. The estimates are likely to include both under- and over-estimates of the actual costs. Emerging technologies, along with significant investments in research and development, are likely to reduce current health burdens over the next 20+ years. On the other hand, the estimated costs were for only three of the health outcomes projected to increase with climate change; and then only a fraction of the burden of malnutrition was included. According to Caulfied et al. [11], the estimated prevalence of weight-for-age less than -2 SD (a measure of malnutrition) are $18 \%$ for Asia and the Pacific; $6 \%$ for Eastern Europe and Central Asia, and for Latin America and the Caribbean; $21 \%$ for the Middle East and North Africa; $46 \%$ in South Asia; 32\% in Sub-Saharan Africa; and $2 \%$ in high-income countries. In addition, the model used to estimate malnutrition does not take into account new projections that a few degree increase in global mean temperature may render some areas unsuitable for rainfed agriculture; if this occurs, the short-term health consequences would likely be severe.

The costs estimated for adaptation are consistent with other estimates of financial needs for health care investment. Stenberg et al. [18] estimated the costs to scale-up essential child health interventions to reduce by twothirds child mortality under the four MDGs aimed at children's health by 2015 in 75 countries; the countries chosen accounted for $94 \%$ of death among children less than five years of age. The interventions focused on malnutrition, pneumonia, diarrhoea, malaria, and key newborn causes of death. Calculations were bottom-up, based on intervention, country, and year. Costs included programspecific investments needed at national and district levels. 
The authors estimated that an additional US $\$ 52.4$ billion would be required for the period 2006-2015. Projected costs in 2015 were equivalent to increasing the average total health expenditures from all financial resources in the 75 countries by $8 \%$ and raising general government health expenditure by $26 \%$ over 2002 levels. The authors noted that countries with weak health care systems may experience difficulties mobilizing enough domestic public funds.

Kiszewski et al. [19] estimated that US\$ 38 to 45 billion would be required from 2006 to 2015 to scale up current malaria control programs to reach international goals, or about US\$ 3.8 to 4.5 billion annually. If resources were to be made available and malaria goals were achieved, then the numbers of climate change-related cases of malaria in 2030 would likely to significantly lower, thus requiring fewer additional resources for treatment than the estimated US\$ $4-12$ billion under the 750 ppm $\mathrm{CO}_{2}$ scenario.

Although current governmental health expenditures can be anticipated to increase with development, there are health problems other than those associated with climate change that need to be addressed, such as HIV/AIDS, tuberculosis, diabetes, and other diseases. Assuming that Ministries of Health, NGOs, and other actors will completely cover the additional costs related to climate change is not realistic for many low-income countries; to do so would mean that other health issues of importance are left wanting. Financial and policy arrangements will need to be altered to address the projected additional cases of diarrhoeal diseases, malnutrition, and malaria.

\section{Conclusion}

Overall, progress is being made in controlling climatesensitive health outcomes. However, much of the progress has been in areas where the health outcomes are easier to control. The world is not on track to meet the healthrelated MDGs by 2015, with climate change working against disease control efforts.

Because the needs for investment in the health sector are large, capacity needs to be built to address climate-sensitive health outcomes. There needs to be increased awareness among Ministries of Health and donors of how climate change could alter the burden of a range of health outcomes, so that appropriate modifications are made in current programs to better address these health outcomes to increase future adaptive capacity. Additional human and financial resources will be needed to prevent and control the projected increased burden of health outcomes due to climate change.

\section{Abbreviations}

$\mathrm{CO}_{2}$ : carbon dioxide; DALYs: Disability Adjusted Life Years; EMF: Energy Modelling Forum; MDGs: Millennium Development Goals; NGOs: Non-Governmental Organizations; ppm: parts per million;UE: unmitigated emissions.

\section{Competing interests}

The author declares that she has no competing interests.

\section{Additional material}

\author{
Additional file 1 \\ WHO regions. Countries within each WHO region, organized by mortal- \\ ity stratum. \\ Click here for file \\ [http://www.biomedcentral.com/content/supplementary/1744- \\ 8603-4-9-S1.doc]
}

\section{Additional file 2}

Global Burden of Disease central and high projections of the relative risk of diarrhoea for alternative climate scenarios relative to baseline climate. Relative risks for diarrhoea in the year 2030 from the WHO Global Burden of Disease study under different climate scenarios.

Click here for file

[http://www.biomedcentral.com/content/supplementary/17448603-4-9-S2.doc]

\section{Additional file 3}

Global Burden of Disease central and high projections of the relative risk of malnutrition for alternative climate scenarios relative to baseline climate. Relative risks for malnutrition in the year 2030 from the WHO Global Burden of Disease study under different climate scenarios.

Click here for file

[http://www.biomedcentral.com/content/supplementary/17448603-4-9-S3.doc]

\section{Additional file 4}

Global Burden of Disease central and high projections of the relative risk of malaria for alternative climate scenarios relative to baseline climate. Relative risks for malaria in the year 2030 from the WHO Global Burden of Disease study under different climate scenarios.

Click here for file

[http://www.biomedcentral.com/content/supplementary/17448603-4-9-S4.doc]

\section{Acknowledgements}

The author would like to thank Joel Smith, Marie-Karin Godbout, Erik Haites, and members of the United Nations Framework Convention on Climate Change Secretariat for their helpful comments. This work was partially conducted under contract with the United Nations Framework Convention on Climate Change Secretariat.

\section{References}

I. Food and Agricultural Organization: The state of food insecurity around the world Rome, Italy: FAO; 2005.

2. Kosek M, Bern C, Guerrent RL: The global burden of diarrhoeal disease, as estimated from studies published between 1992 and 2000. Bull World Health Organ 2003, 8I:197-204. 
3. WHO: World Health Report 2004 - changing history Geneva: World Health Organization; 2004.

4. Confalonieri U, Menne B, Akhtar R, Ebi KL, Hauengue M, Kovats RS, Revich B, Woodward A: Human Health. In Climate Change 2007: Impacts, Adaptation and Vulnerability. Contribution of Working Group II to the Fourth Assessment Report of the Intergovernmental Panel on Climate Change Edited by: Parry ML, Canziani OF, Palutikof JP, van der Linden PJ, Hanson CE. Cambridge, UK: Cambridge University Press; 2007:39I-43I.

5. McMichael AJ, Campbell-Lendrum D, Kovats S, Edwards S, Wilkinson P, Wilson T, Nicholls R, Hales S, Tanser F, LeSueur D, Schlesinger M, Andronova N: Global Climate Change. In Comparative Quantification of Health Risks: Global and Regional Burden of Disease due to Selected Major Risk Factors Edited by: Ezzati M, Lopez A, Rodgers A, Murray C. Geneva: World Health Organization; 2004: I543-1649.

6. Murray CHL, Ezzati M, Lopez AD, Rodgers A, Hoorn S Vander: Comparative quantification of health risks: conceptual framework and methodological issues. Population Health Metrics 2003 [http://www.pophealthmetrics.com/content/I/I/I] accessed I May 2007

7. Johns TC, Gregory JM, Stott PA, Mitchell JFB: Correlations between patterns of 19 th and 20 th century surface temperature change and HadCM2 climate model ensembles. Geophysical Research Letters 200I, 28:1007-10.

8. Energy Modelling Forum: Second round study design for EMFI4. In EMF Working Paper No. I 4. I Stanford, CA: Energy Modelling Forum; 1995.

9. IBSNAT: International benchmark sites network for agrotechnology transfer. In Decision Support System for Agrotechnology Transfer Version 2.I (DSSAT V2.I) University of Hawaii, HI: Department of Agronomy and Soil Science, College of Tropical Agriculture and Human Resources; 1989.

10. Keusch GT, Fontaine O, Bhargava A, Boschi-Pinto C, Bhutta ZA, Gotuxxo E, Rivera J, Chow J, Shahid-Salles SA, Laxminarayan R: Diarrhoeal Diseases. Disease Control Priorities in Developing Countries. 2003:37I-387 [http://www.dcp2.org]. accessed I May 2007

II. Caulfield LE, Richard SA, Rivera JA, Musgrove P, Black RE: Stunting, wasting, and micronutrient deficiency disorders. Disease Control Priorities in Developing Countries 2003:55I-567 [http:// www.dcp2.org]. accessed I May 2007

12. Edejer TT-T, Aikins M, Black R, Wolfson L, Hutubessy R, Evans DB: Cost effectiveness analysis of strategies for child health in developing countries. BMJ 2005

13. Morrel CM, Lauer JA, Evans DB: Cost effectiveness analysis of strategies to combat malaria in developing countries. $B M J$ 2005.

14. Hecht R, Shah R: Recent trends and innovations in development assistance for health. Disease Control Priorities in Developing Countries 2003:243-254 [http://www.dcp2.org]. accessed I May 2007

15. United Nations: Population Division of the Department of Economic and Social Affairs of the United Nations Secretariat, World Population Prospects: The 2006 Revision and World Urbanization Prospects: The 2005 Revision. 2006 [http:// esa.un.org/unpp]. downloaded August 2I, 2008

16. Ebi $\mathrm{KL}$ : Healthy people 2100: modeling population health impacts of climate change. Climatic Change 2008, 88:5-19.

17. Bosello F, Roson R, Tol RSJ: Economy-wide estimates of the implications of climate change: Human health. Ecological Economics 2006, 58:579-91.

18. Stenberg J, Johns B, Scherpbier RW, Edeger TT-T: A financial road map to scaling up essential child health interventions in $\mathbf{7 5}$ countries. Bulletin WHO 2007, 5:305-3I4.

19. Kiszewski A, Johns B, Schapria A, Delacollette C, Crowell V, TanTorres T, Ameneshewa B, Teklehaimanot A, Nafo-Traore F: Estimated global resources needed to attain international malaria control goals. Bull World Health Organ 2007, 85:623-630.

\section{Publish with Bio Med Central and every} scientist can read your work free of charge

"BioMed Central will be the most significant development for disseminating the results of biomedical research in our lifetime. "

Sir Paul Nurse, Cancer Research UK

Your research papers will be:

- available free of charge to the entire biomedical community

- peer reviewed and published immediately upon acceptance

- cited in PubMed and archived on PubMed Central

- yours - you keep the copyright

Submit your manuscript here:

http://www.biomedcentral.com/info/publishing_adv.asp
BiolMedcentral 